\title{
Quasi-static cyclic tests of two mixed reinforced concrete-unreinforced masonry wall structures
}

\author{
Alessandro Paparo ${ }^{\mathrm{a}, 1}$, Katrin Beyer ${ }^{\mathrm{b}, *}$ \\ ${ }^{a}$ Earthquake Engineering and Structural Dynamics Laboratory (EESD), School of Architecture, Civil and Environmental Engineering (ENAC), École Polytechnique Fédérale de \\ Lausanne (EPFL), EPFL ENAC IIC EESD, GC B2 515, Station 18, CH-1015 Lausanne, Switzerland \\ ${ }^{\mathrm{b}}$ Earthquake Engineering and Structural Dynamics Laboratory (EESD), School of Architecture, Civil and Environmental Engineering (ENAC), École Polytechnique Fédérale de \\ Lausanne (EPFL), EPFL ENAC IIC EESD, GC B2 504, Station 18, CH-1015 Lausanne, Switzerland
}

\section{A R T I C L E I N F O}

\section{Article history:}

Received 14 May 2013

Revised 1 April 2014

Accepted 3 April 2014

Available online 4 May 2014

\section{Keywords:}

Seismic behaviour

Mixed wall structures

Reinforced concrete

Unreinforced masonry

Large scale tests

\begin{abstract}
A B S T R A C T
In several seismic countries, residential buildings are constructed using both reinforced concrete (RC) and unreinforced masonry (URM) walls. Despite their popularity, there is a general lack of knowledge concerning the seismic behaviour of such mixed systems and they are often designed using oversimplifying assumptions. For this reason, a research programme was initiated at EPFL with the objective of contributing to the understanding of the seismic behaviour of such structures. This paper presents two quasistatic cyclic tests on two-third scale models of a prototype structure. The two specimens are composed of a two-storey RC wall coupled to a two-storey URM wall by means of RC beams. The horizontal forces were applied at the two floor levels. The main difference between the two test units was the axial load applied at the top of the walls. A particular test set-up allowed measuring the reaction forces (axial force, shear force and bending moment) at the base of the URM wall. From the applied horizontal and vertical loads the reaction forces at the base of the RC wall were computed. It was hence possible to backcalculate the distribution of the reaction forces between the two walls. The article describes the design of the test units, the test set-up and the damage evolution during testing. The main results are summarised and behaviour patterns of mixed RC-URM wall structures identified.
\end{abstract}

(c) 2014 Elsevier Ltd. All rights reserved.

\section{Introduction}

Existing unreinforced masonry (URM) buildings, which do not pass the seismic design check, are often strengthened by adding RC walls to the existing structure or by replacing selected URM walls with RC ones. The RC walls herein considered are designed for developing a stable flexural response and failing for larger displacement demands than the URM walls. In Switzerland, such mixed construction technique is also adopted for new residential buildings of 3-6 storeys. Despite the popularity of these mixed constructions, very little is known about their seismic behaviour, as only few studies were carried out in the past [1]. As a consequence, codes do not provide guidelines for mixed RC-URM wall structures and design engineers, when conceiving such structures, often adopt oversimplified assumptions. As an example, in Switzerland typically only the lateral stiffness and strength of the

\footnotetext{
* Corresponding author. Tel.: +4121 6936234/6935706.

E-mail addresses: alessandro.paparo@epfl.ch (A. Paparo), katrin.beyer@epfl.ch (K. Beyer).

1 Tel.: +41216936321.
}

$\mathrm{RC}$ walls is taken into account for the seismic design of mixed RC-URM wall buildings. In most building configurations the URM walls outnumber, however, the RC walls and, as the paper will show, influence therefore significantly the lateral stiffness and strength of the building.

Numerical studies on mixed RC-URM wall structures [2-6] confirmed that URM walls have to be considered when realistic estimates of the structure's stiffness and strength are sought. For example, since the global response of mixed RC-URM wall structures is influenced by both types of walls, the displacement profiles of mixed RC-URM wall structures differ from those of buildings with RC or URM walls only. At the same time, numerical results are very sensitive to the modelling assumptions [2,3] but the models could not be validated since experimental evidence on the seismic behaviour of mixed RC-URM wall structures was lacking [1]. Non-linear static analyses on mixed RC-URM structures were carried out by Cattari and Lagomarsino [4]. However, their analyses focused on mixed structures with RC walls designed for vertical loads only. As a consequence, the RC walls failed before the URM ones and decreased the displacement ductility capacity of the mixed structure when compared to a regular URM building. 
Only two experimental campaigns on mixed RC-URM structures were conducted in the past (apart from RC frames with URM infills). The first study consisted of shake table tests on a URM wall building with one RC column [7]. Nevertheless, the latter had no influence on the behaviour of the structure under lateral loads since the URM walls were considerably stiffer than the RC column. Therefore these tests cannot be used as benchmark for the seismic evaluation of mixed RC-URM wall structures. An additional study dealt with the behaviour of a mixed structure composed of URM walls and one RC frame on the ground floor [8-14]. Coupling the two systems vertically addresses, however, very different issues then the horizontal coupling. The authors of this study also investigated different strengthening solutions including one which consisted in adding a RC central core wall connected to the foundation by means of a rubber plate $[13,14]$. Hence, none of the experimental studies addressed the seismic behaviour of mixed RC-URM wall structures where RC and URM walls are continuous over the height and the $\mathrm{RC}$ walls fixed to the foundation. Moreover, existing studies only addressed the global behaviour and not the contribution of the individual components. For this reason, an experimental campaign was initiated at the École Polytechnique Fédérale de Lausanne (EPFL) in which both dynamic and quasi-static cyclic tests on mixed RC-URM wall structures were performed.

This paper describes the results of the quasi-static cyclic tests on two units representing two-third scale models of a prototype structure. The two-storey test units are composed of a RC wall and a URM wall which are coupled by means of RC beams. The test setup is particular as it allows measuring the reaction forces at the base of the URM wall. The objective of the test is to provide high quality experimental data for (i) calibrating and evaluating numerical and analytical models and (ii) investigating the contribution of the URM and RC walls to the system's strength, stiffness, deformed shape and displacement capacity. Following this introduction, Section 2 describes the design of the test units and the test set-up. Section 3 continues with the presentation of the test results and their discussion. A summary of the most important features of the behaviour of mixed RC-URM wall structures when subjected to lateral loading is presented in Section 4, which concludes with an outlook on future research activities.

\section{Experimental investigations}

Two large scale specimens were constructed and tested the structural engineering laboratory of EPFL. In the following, the geometry of the test units, their relationship with a fictitious four storey mixed reference structure, the material properties, the test set-up and the loading history are described.

\subsection{Test units and reference structure}

Each of the two test units comprised a two-storey URM wall coupled to a two-storey RC wall by two RC beams. The main difference between the two systems was the axial load applied at the top of the walls. For the first system (TU1), an axial load of $400 \mathrm{kN}$ was applied at the top of the URM wall leading to a behaviour of the latter controlled by shear deformations; for the second test (TU2) the axial load was reduced to $200 \mathrm{kN}$ in order to achieve a prevalent rocking behaviour of the URM wall. The RC walls of TU1 and TU2 were subjected to axial loads of $125 \mathrm{kN}$ and $0 \mathrm{kN}$, respectively.

Each test unit aimed at representing the most critical elements of a mixed RC-URM wall structure. The reference structure is a four storey building (Fig. 1) with three URM walls and one RC wall. The walls are coupled at the floor levels by means of RC slabs. Due to the shear forces transferred by the RC slabs, the axial forces in the external walls vary when the building is subjected to lateral loading, whereas it is almost constant in the internal walls since RC slabs of equal strength and length frame into these walls from both sides.

The most interesting part of the reference structure comprises the two lower storeys of the two external walls: the walls are expected to fail in the lower storeys and, since the behaviour of URM and RC walls is sensitive to the variation of axial force, the outer walls are of particular concern. The test units represented therefore the two lower storeys of the outer walls of the reference structure. The storey height of the specimens was $1.61 \mathrm{~m}$, which corresponds approximately to two thirds of the storey height of a full-scale structure. The length of the URM and RC wall were $2.1 \mathrm{~m}$ and $0.8 \mathrm{~m}$, respectively; the width of both walls was $0.15 \mathrm{~m}$.

The length of the URM walls was not scaled by a factor of $2 / 3$ in order to increase their influence on the overall behaviour of the test units, as the number of URM walls from the reference structure to the specimens was reduced from 3 to 1 . The RC beams, connecting the two walls, had a cross section of $0.45 \times 0.2 \mathrm{~m}$ (width $\times$ height) and represented the effective width of the slabs in the reference structure. According to Priestley et al. [15], the effective width of slabs coupling internal walls can be estimated as three times the wall thickness. The two RC beams were designed to provide approximately the same variation of axial force at the wall base as in the reference structure. Pushover analyses of the reference structure and the test unit showed that the behaviour of the test unit is representative of the behaviour of the reference structure with regard to the failure mechanism of the URM wall and the redistribution of axial force between the two walls.

The URM walls were constructed using hollow clay bricks which, according to EN 1996-1 [16], belong to "Group 2". Furthermore, the selected brick type has continuous longitudinal webs (Fig. 3), which are necessary for carrying the in-plane shear forces of the masonry walls. The thickness of the bed joints was $1 \mathrm{~cm}$ with dry vertical joints. The RC walls are "model" capacity-designed ductile walls and the RC beams are designed to develop a stable flexural mechanism. The reinforcement layouts of RC walls and $\mathrm{RC}$ beams are shown in Fig. 2a and b, respectively.

\subsection{Material properties of the test units}

In addition to the two quasi-static experiments, material tests on bricks, mortar, masonry wallets, concrete and reinforcing bars were carried out. In the following, the most important material properties are summarised. The masonry walls were constructed using hollow-core tongue-and-groove clay bricks with standard dimensions of $300 \times 190 \times 150 \mathrm{~mm}$ (length $\times$ height $\times$ thickness, Fig. 3). E-moduli and strength of the bricks were determined according to EN 772-1 [17] and the results are summarised in Table 1. The mortar was a standard cement mortar (Weber Mur 720 ). The bed joints had an average thickness of $1 \mathrm{~cm}$; the head joints were not filled. The E-modulus, compressive strength and Poisson's ratio of the masonry were determined according to EN 1052-1 [18] and are summarised in Table 2. Triplet tests according to EN 1052-3 [19] were used to determine the interface strength between mortar and bricks. Table 3 summarises the Mohr-Coulomb relationships characterising the peak and residual shear strength of the bed joints.

The mechanical properties of the concrete are given in Table 4. Each test unit was cast with two batches of concrete: the first batch was used to construct the foundation and the first storey wall, the second one to build the second storey wall and the two beams. Table 5 summarises the mechanical properties (yield and tensile strength) of the reinforcing steel in beams and walls. 


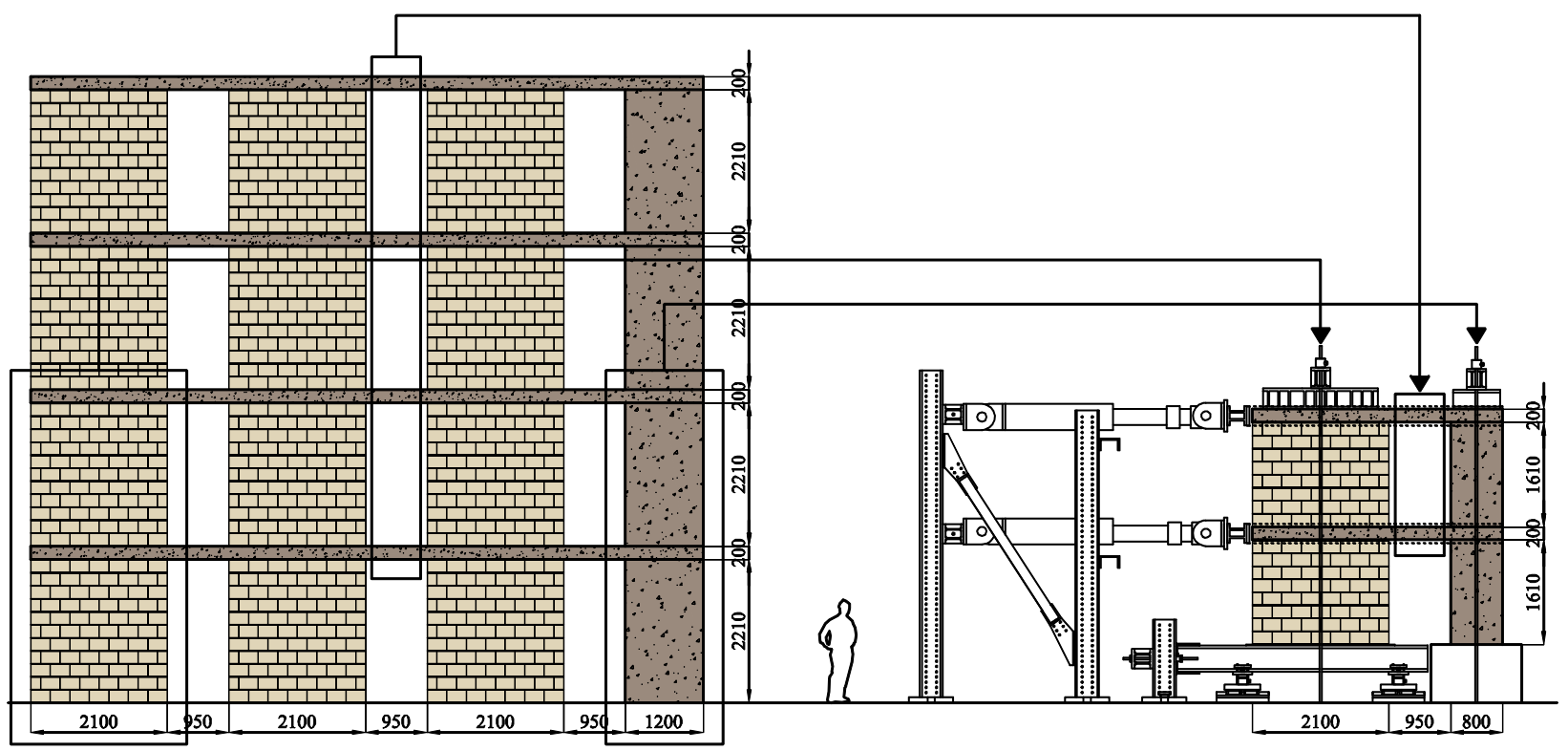

Fig. 1. Reference structure and test unit: the elements of the reference structure represented in the test units are encircled (all dimensions in mm).

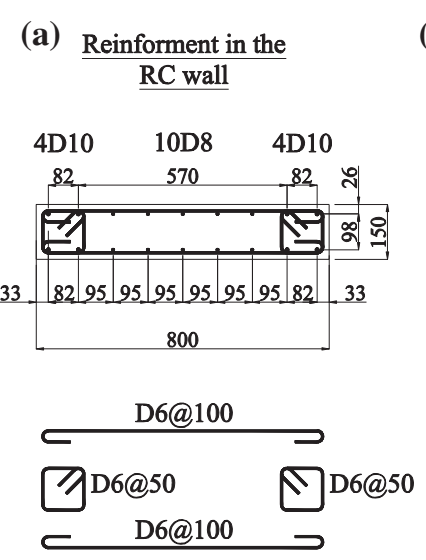

(b)

$\underline{\text { Reinforment in the }}$ $\mathrm{RC}$ beams

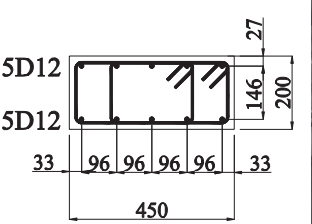

2 D6@65, pos 2 2 D6@130,pos 1

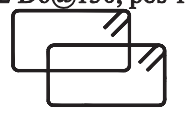

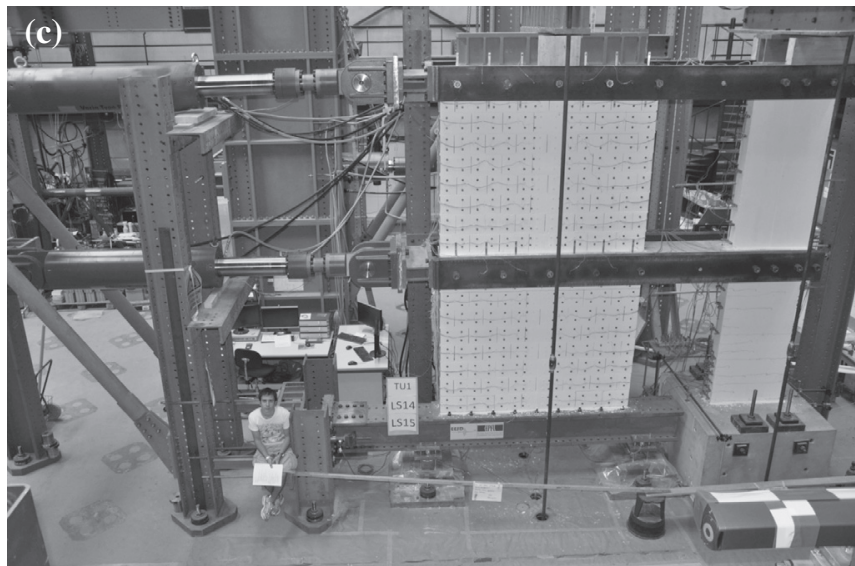

Fig. 2. Reinforcement layouts of TU1 and TU2: (a) reinforcement layout of RC walls, (b) reinforcement layout of RC beams, (c) test set-up showing TU1.
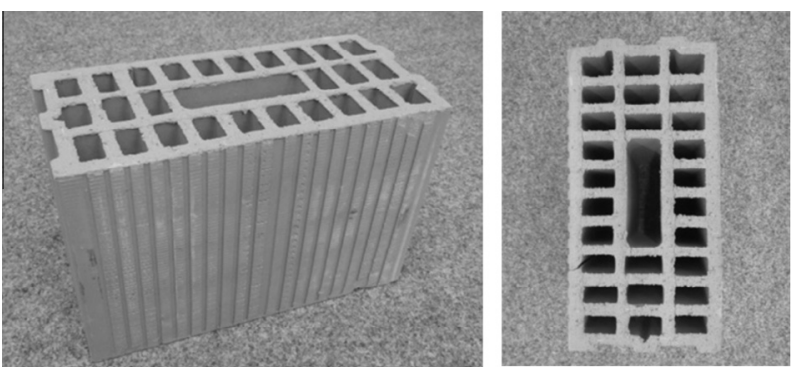

Fig. 3. Brick type used for the construction of TU1 and TU2.

\subsection{Test set-up and instrumentation}

The behaviour of a mixed RC-URM wall structure depends largely on the relative contribution of URM and RC walls to the system's stiffness and strength. To determine the forces carried by the
Table 1

Mechanical properties of the bricks (median values and standard deviations).

\begin{tabular}{lllll}
\hline Test unit & $E_{b x}(\mathrm{GPa})$ & $E_{b y}(\mathrm{GPa})$ & $f_{c b x}(\mathrm{MPa})$ & $f_{c b y}(\mathrm{MPa})$ \\
\hline TU1 and TU2 & $9.8 \pm 2.7$ & $4.7 \pm 2.0$ & $23.5 \pm 1.9$ & $8.4 \pm 0.1$ \\
\hline
\end{tabular}

$E_{b x}$ and $E_{b y}$ : E-moduli for loading along the brick's height and length, respectively. $f_{c b x}$ and $f_{c b y}$ : Compressive strength for loading along the brick's height and length.

Table 2

Mechanical properties of the mortar $\left(f_{t m}, f_{c m}\right)$ and masonry wallets $\left(E_{C M}, f_{c M}\right.$ and $\left.v\right)$.

\begin{tabular}{lcclll}
\hline Test unit & $f_{t m}(\mathrm{MPa})$ & $f_{c m}(\mathrm{MPa})$ & $E_{c M}(\mathrm{GPa})$ & $f_{c M}(\mathrm{MPa})$ & $v_{M}(-)$ \\
\hline TU1 & $5.2 \pm 0.6$ & $29.2 \pm 3.8$ & $5.2 \pm 0.8$ & $4.8 \pm 0.8$ & $0.21 \pm 0.12$ \\
TU2 & $4.8 \pm 0.5$ & $29.5 \pm 3.1$ & $5.0 \pm 0.7$ & $7.8 \pm 0.6$ & $0.14 \pm 0.01$ \\
\hline
\end{tabular}

$f_{t m}$ and $f_{c m}$ : Tensile and compressive strength of mortar [20].

$E_{c M}, f_{c M}$ and $v_{M}$ : E-modulus, compressive strength and Poisson's ratio of masonry panels subjected to compression orthogonal to bed-joints [18]. 
Table 3

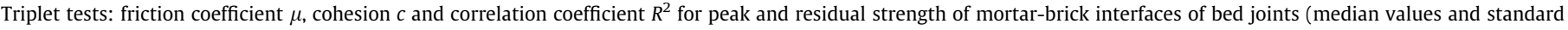
deviations).

\begin{tabular}{|c|c|c|c|c|c|c|}
\hline \multirow[t]{2}{*}{ Mohr-Coulomb relationship } & \multicolumn{3}{|l|}{ TU1 } & \multicolumn{3}{|l|}{ TU2 } \\
\hline & $\mu(-)$ & $c(\mathrm{MPa})$ & $R^{2}(-)$ & $\mu(-)$ & $c(\mathrm{MPa})$ & $R^{2}(-)$ \\
\hline Peak stress: $\tau_{\max }=\mu_{\text {peak }} \sigma+c_{\text {peak }}$ & 0.60 & 0.41 & 0.90 & 0.67 & 0.35 & 0.94 \\
\hline Residual stress: $\tau_{\text {res }}=\mu_{\text {res } 1} \sigma+c_{\text {res } 1}$ & 0.67 & 0.13 & 0.90 & 0.68 & 0.09 & 0.98 \\
\hline Residual stress: $\tau_{\text {res }}=\mu_{\text {res } 2} \sigma$ & 0.99 & 0.00 & 0.68 & 0.89 & 0.00 & 0.88 \\
\hline
\end{tabular}

Table 4

Mechanical properties of the concrete (median values and standard deviations).

\begin{tabular}{lllll}
\hline Test unit & $f_{c}(\mathrm{MPa})$ & $E_{c}(\mathrm{GPa})$ & $f_{t c}(\mathrm{MPa})$ & $f_{28 c}^{\prime}(\mathrm{MPa})$ \\
\hline TU1, Batch 1 & $57.8 \pm 0.9$ & $36.2 \pm 0.5$ & $4.6 \pm 0.3$ & $50.2 \pm 2.2$ \\
TU1, Batch 2 & $45.4 \pm 1.5$ & $32.9 \pm 1.3$ & $3.6 \pm 0.2$ & $38.1 \pm 1.7$ \\
TU2, Batch 1 & $60.3 \pm 0.5$ & $35.6 \pm 0.4$ & $4.4 \pm 0.3$ & $52.6 \pm 0.9$ \\
TU2, Batch 2 & $47.9 \pm 1.8$ & $35.4 \pm 1.9$ & $3.7 \pm 0.3$ & 43.6
\end{tabular}

$f_{c}^{\prime}, E_{c}, f_{t c}$ : Cylinder compression strength, E-modulus and tensile strength obtained from double punch tests on half cylinders $[21,22]$ at the day of testing of TU1 and TU2, respectively.

$f_{28 c}$ : Cylinder compression strength after 28 days.

Table 5

Properties of reinforcing steel (median values and standard deviations).

\begin{tabular}{llll}
\hline Test unit and bar diameter & $f_{y}(\mathrm{MPa})$ & $f_{t}(\mathrm{MPa})$ & $f_{t} / f_{y}(-)$ \\
\hline TU1 and TU2: D12 mm bars & $527.0 \pm 7.5$ & $608.5 \pm 8.4$ & 1.155 \\
TU1: D10 mm bars & $526.8 \pm 1.4$ & $618.9 \pm 5.1$ & 1.175 \\
TU2: D10 mm bars & $549.9 \pm 0.4$ & $617.5 \pm 6.1$ & 1.123 \\
TU1 and TU2: D8 mm bars & $544.2 \pm 10.2$ & $661.2 \pm 5.4$ & 1.215 \\
TU1 and TU2: D6 mm bars & 471.3 & $613.9 \pm 4.5$ & 1.303 \\
\hline
\end{tabular}

$f_{y}, f_{t}$ : Yield strength and tensile strength of the reinforcing steel.

URM wall of the test unit, a particular test set-up was developed that allowed measuring the reaction forces (axial force, bending moment, shear force) at the base of the URM wall (Figs. 2c and 4a). The URM wall was constructed on one stiff steel beam supported by two systems of sliders and load cells measuring the variation of axial force and bending moment during the test. In addition, the variation of shear force at the base of the URM wall was measured by a system of load cells and rotational hinges at the left end of the steel beam. Fig. 5a shows a close-up of the steel beam with the systems measuring the horizontal and vertical reaction forces at the base of the URM wall. The functionality of the system was verified before the construction of the first test unit by applying different configurations of horizontal and vertical forces of known magnitude to the steel beam. The RC wall was connected to the strong floor through a RC foundation. According to Fig. $5 \mathrm{~b}$, the reaction forces (variation in axial force $\Delta N_{U R M}$ due to the applied horizontal forces, shear force $V_{U R M}$ and bending moment $M_{U R M}$ ) at the base of the URM wall can be calculated as follows:

$\Delta N_{U R M}=N_{1}+N_{2}-N_{3}$

$V_{U R M}=H$

$M_{U R M}=\left(-N_{1}+N_{2}\right) \cdot a+N_{3} \cdot b+V_{U R M} \cdot c$

where $N_{1}$ and $N_{2}$ are the vertical reaction forces and $H$ the horizontal force in the steel beam corresponding to the base shear in the URM wall. The parameters $a, b$ and $c$ are the lever arms of the reaction forces with respect to the centre of the URM wall (Point A, Fig. 5b) and are equal to $1.200 \mathrm{~m}, 2.445 \mathrm{~m}$ and $0.220 \mathrm{~m}$, respectively. $N_{3}$ is a parasitic force caused by the friction in the two rotational hinges which are part of the system measuring the horizontal reaction force. This force $N_{3}$ is considered when computing the axial force $\Delta N_{U R M}$ and the bending moment $M_{U R M}$ at the base of the URM wall; $N_{3}$ can account for up to $2 \%$ of the variation in axial force $\Delta N_{U R M}$ and $4 \%$ of the moment $M_{U R M}$.

The external forces acting on the system are: (i) the two horizontal forces $\left(F_{a c t}\right)$ that are applied by the two horizontal actuators, (ii) the vertical forces applied by the system of hollow core jacks and rods, (iii) the self-weight of the test unit and (iv) the weight of the parts of the test set-up that were supported by the test unit. From the external forces and the measured reaction forces at the base of the URM wall, the reaction forces at the base of the RC wall can be back-calculated (variation in axial force $\Delta N_{R C}$ due to applied horizontal forces, shear force $V_{R C}$ and bending moment $M_{R C}$ ):

$\Delta N_{R C}=-\Delta N_{U R M}$

$V_{R C}=V_{\text {tot }}-V_{U R M}$

$M_{R C}=O T M-M_{U R M}-\Delta N_{U R M} \cdot L_{\text {base }}$

where $L_{\text {base }}$ is equal to $2.400 \mathrm{~m}$ and corresponds to the distance between the wall axes. The total overturning moment OTM at the base of the walls equates to:

$O T M=F_{a c t} \cdot d_{1}+F_{a c t} \cdot d_{2}$

where $d_{1}$ is equal to $1.710 \mathrm{~m}$ and $d_{2}$ is equal to $3.520 \mathrm{~m}$; they correspond to the height of the two horizontal actuators above the base of the walls (Fig. $4 \mathrm{a}$ ). The shear forces $V_{U R M}$ and $V_{R C}$ as well as the bending moments $M_{U R M}$ and $M_{R C}$ were considered positive for the positive loading direction (see arrows in Fig. 4a).

The axial load was applied at the top of the walls by means of vertical rods and hollow core jacks (Fig. 4a) and kept constant during the test. A frame behind the test unit prevented out-of-plane deformations during testing (Fig. 4b). The axial force at the base of the two walls $N_{U R M}$ and $N_{R C}$ was calculated by adding to the variation of the axial force $\left(\Delta N_{U R M}, \Delta N_{R C}\right)$ the vertical forces applied by the hollow core jacks and rods $\left(W_{1}\right.$ and $W_{2}$, Fig. 6) plus the selfweight of the test unit and the parts of the test set-up that were supported by the URM wall $(\sim 60 \mathrm{kN})$ and the RC wall $(\sim 25 \mathrm{kN})$ :

$N_{U R M}=\Delta N_{U R M}+W_{1}+60 \mathrm{kN}$

$N_{R C}=\Delta N_{R C}+W_{2}+25 \mathrm{kN}$

In Eqs. (8) and (9) a compression axial force at the base of the walls was considered as positive. For the positive loading direction the axial force at the base of the RC wall increases while the axial force at the base of the URM wall decreases (see arrows in Fig. 4a). During the quasi-static cyclic test, the servo-controlled actuator at the second storey applied a sequence of cyclic lateral displacements (Fig. 4a). The actuator of the first storey was slaved to the one of the second storey to apply the same horizontal force. A fixed load rather than a fixed displacement pattern was applied since the drift profile of the mixed system was one of the sought output quantities (for further information on quasi-static tests on systems with 
(a)

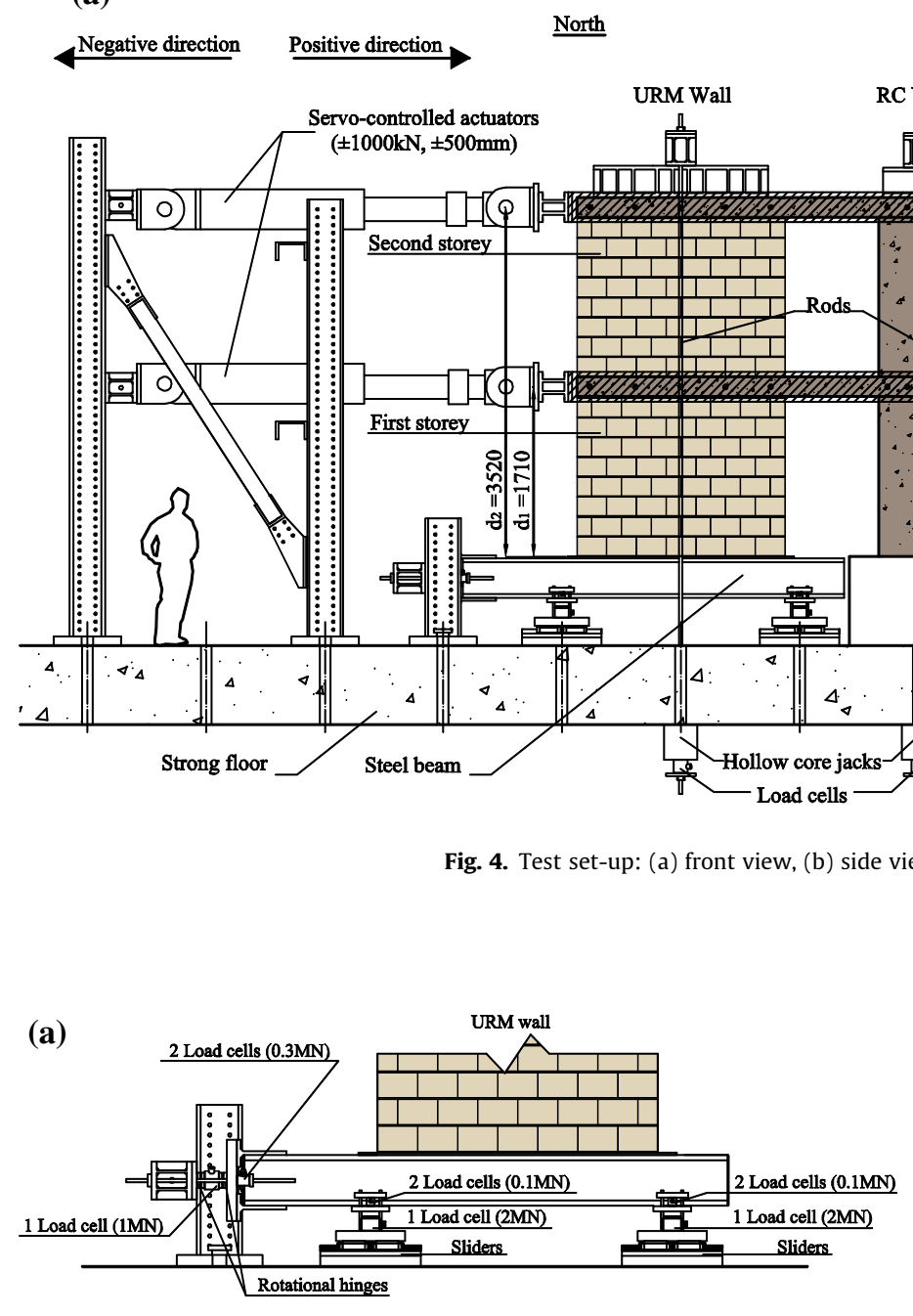

(b)
LVDTs for measuring

the top displacement

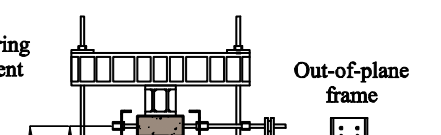

- :

$(\Delta$ top $)$

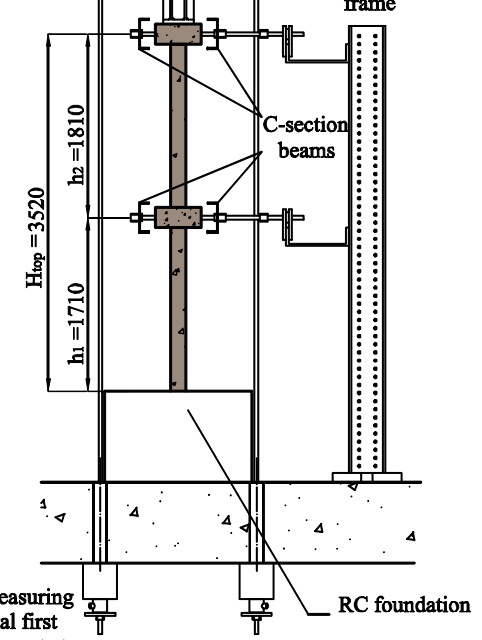

the horizontal first
storey displacement $\left(\Delta_{1}\right)$

dimensions in $\mathrm{mm}$.

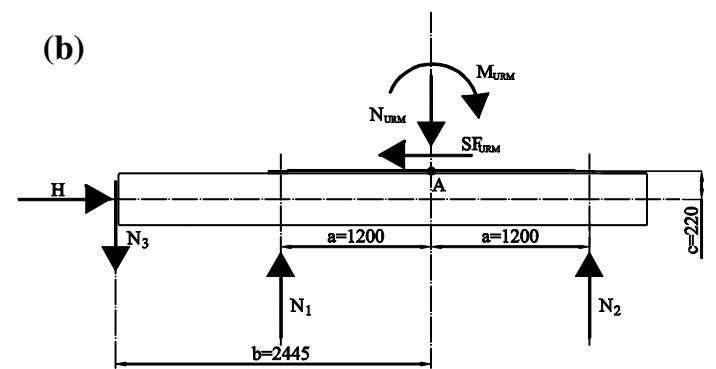

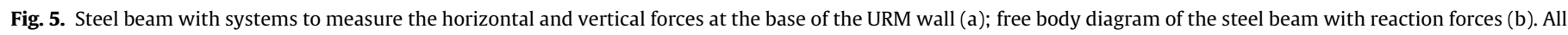
dimensions in $\mathrm{mm}$.

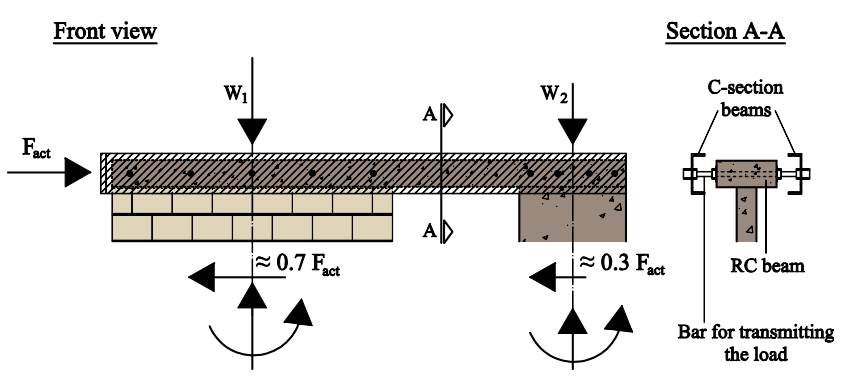

Fig. 6. System of C-section beams and bars to distribute the applied horizontal forces along the length of the RC beams: front view and section.

several storeys see [23]). The actuator forces $F_{\text {act }}$ were transferred to the two walls through two C-section beams attached to the outer edges of the RC beam by means of nine bars per storey. The nine bars allowed distributing the horizontal load along the length of the RC beam. A rather similar system for distributing the horizontal loads in coupled wall systems is documented in [24]. Applying a concentrated force at the end of the RC beam, which is often done in quasi-static cyclic tests, would have introduced an additional axial force in the coupling beams, which would have modified their moment capacity. The final bar configuration is shown in Fig. 6. The bars did not all transmit the same force, since the deformation of the C-section beams between two bars was not negligible. With the chosen bar configuration, approximately $70 \%$ of the lateral load was applied to the URM wall and 30\% to the RC one; this distribution corresponds approximately to the ratio of the wall lengths, which are taken as indicator for the size of the tributary areas of the walls.

During the tests, in addition to the forces, a significant number of global and local deformation quantities were measured. The horizontal top displacement $\left(\Delta_{\text {top }}\right.$ ), the horizontal first storey displacement $\left(\Delta_{1}\right)$ and the displacements of the foundations were measured by means of linear variable differential transformers (LVDTs). Strain-gauges were placed along the central longitudinal bars of the RC beams. The elongation of the edges of the RC wall was measured by chains of LVDTs; the shear displacement of the RC wall was measured by diagonal string pots. The deformation pattern of the URM wall was recorded using the LED based optical measurement "Optotrak" from NDI [25]. Additional LEDs were placed on the RC beams, the steel foundation and the C-section beams. At peak displacements and when the horizontal load was zero, the width of selected cracks was measured manually. In the 

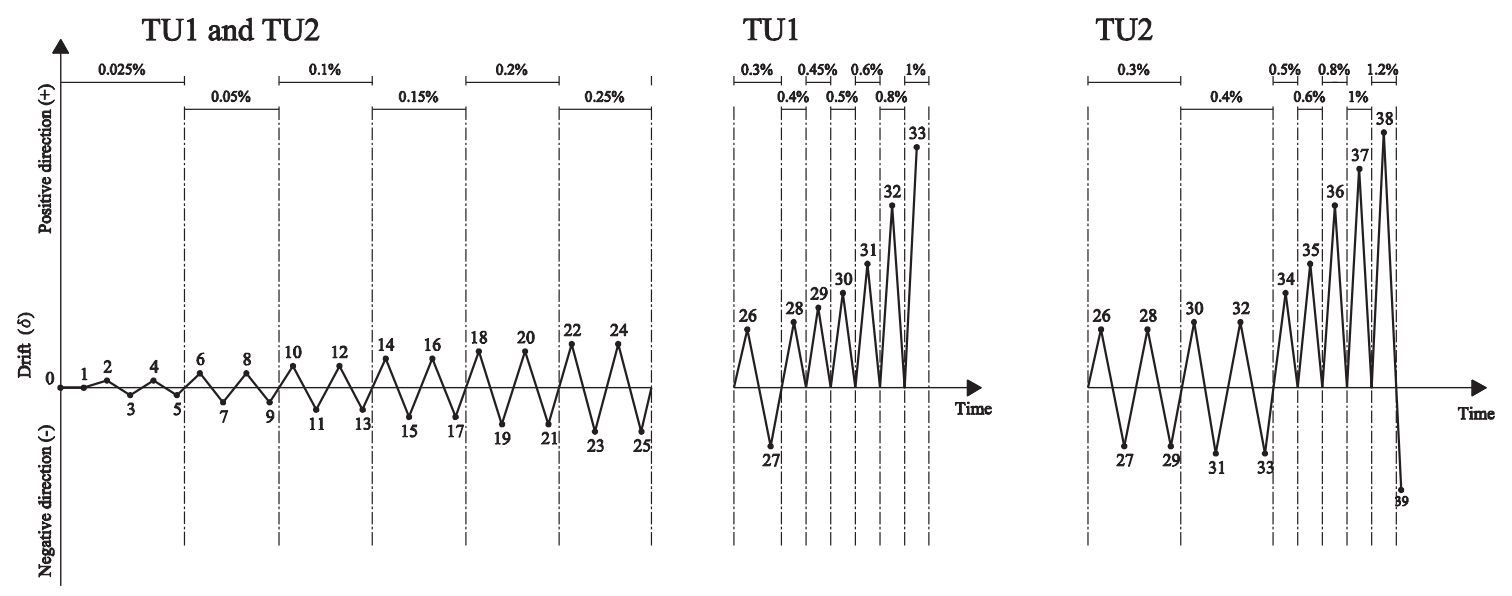

Fig. 7. Loading history for TU1 and TU2.

following, "peak crack width" is referred to the crack width measured at the peak displacement, while "residual crack width" to the measurements when the horizontal load was zero.

\subsection{Loading history}

The loading history comprised two fully reversed cycles with increasing amplitudes up to a drift $\delta_{c}$ for which the strength dropped for one loading direction by more than $10 \%$. For both test units, this drop in strength was first attained in the negative loading direction (TU1: $\delta_{c}=-0.3 \%$; TU2: $\delta_{c}=-0.4 \%$ ). After the drift $\delta_{c}$, to avoid a premature axial load failure of the URM wall, the test was continued with half cycles in the positive direction only. The drift of the structure $\delta$ (average drift) was defined as the ratio of horizontal top displacement $\left(\Delta_{t o p}\right)$ and height of the structure $\left(H_{\text {top }}\right)$. The amplitudes of each half-cycle are shown in Fig. 7 . The definition of the positive and negative directions is indicated in Fig. 4a. After each load step the loading was stopped, photos were taken and cracks were marked. The drift controlled load steps commence with LS2. LS0 refers to the state before any displacements or forces were applied (zero measurements). LS1 refers to the load state when the axial loads at the top of the walls were applied and the servo-hydraulic actuators for the horizontal loads were connected.

\section{Test results}

This section presents selected test results of TU1 and TU2 which illustrate the global behaviour of the specimens and their failure mechanisms (Section 3.1) as well as the distribution of the reaction forces between the two walls (Section 3.2). The objective is to provide experimental evidence required for validating numerical or analytical models of mixed RC-URM wall structures and to yield insights into the seismic behaviour of such structures. In the following, the term horizontal load failure describes the shear strength degradation of one wall by $20 \%$ of its maximum strength. Axial load failure describes the loss of axial load bearing capacity in one of the URM walls.

\subsection{Global behaviour of the test units and their failure mechanisms}

\subsubsection{Distribution of the inter-storey shear drifts}

The distribution of inter-storey shear drifts over the height of the structure yields insights into the interaction of URM and RC walls. For the first and second storey, the inter-storey shear drift $\delta_{s}$ was calculated as follows:
$\delta_{s}=\frac{\Delta_{i}-\Delta_{j}}{h}-\theta_{i}-\left(\theta_{j}-\theta_{i}\right)$

where $\Delta_{i}, \Delta_{j}, \theta_{i}$ and $\theta_{j}$ are the horizontal displacements and rotations of the beams underneath and above the selected storey and were calculated from the optical measurements [25]. The horizontal displacements $\left(\Delta_{i}, \Delta_{j}\right)$ were considered positive for the positive loading direction (see arrows in Fig. 4a); the beam rotations $\left(\theta_{i}\right.$, $\theta_{i}$ ) were considered positive when clockwise.

Fig. 8 shows that for the positive loading direction of TU1, the shear deformations of the second storey of TU1 are larger than that of the first storey, while for TU2 the shear deformations of the two storeys are comparable. Indeed, TU1 coupled a RC flexural wall to a URM wall where shear deformations prevailed, leading to large shear forces in the second storey of the URM wall. On the contrary, in TU2 the URM wall displayed a rocking behaviour. Since its deformation mode was more similar to the RC wall, it led to smaller shear forces and hence smaller shear deformations of the second storey of the URM wall.

\subsubsection{TU1}

The first crack of TU1 developed at the base of the RC wall. It was a horizontal crack which appeared during the very first cycle $(\delta=0.025 \%)$. Unlike the RC wall, which second storey remained during the entire test uncracked, the URM wall developed simultaneously cracks in the first and second storey: for the positive and negative loading direction inclined shear cracks formed in both storeys during the cycles with $\delta=0.1 \%$. They followed initially the joints $(\delta=0.1 \%)$ but passed soon also through some of the bricks $(\delta=0.15 \%)$. The distribution of damage over the entire height of the URM wall differs from buildings with URM walls only, where damage tends to be concentrated in the first storey.

Similar to the behaviour of RC wall-frame structures, the even damage distribution over the height of the structure results from the mixed structural system including flexure-dominated slender RC walls and shear-dominated URM walls. In mixed RC-URM wall structures, these two systems are coupled at the storey levels by RC beams or slabs, which impose equal horizontal displacements on the two types of walls and cause damage to both storeys of the URM wall [2].

For the negative loading direction, the cracks through the bricks of the first storey soon increased in number and width. At $\delta=-0.3 \%$ the test unit's horizontal strength reduced (LS27, Fig. 9a) and the URM wall featured a horizontal load failure. The URM wall would have also reached axial load failure had the horizontal load not been quickly reduced to zero. The failure mechanism that developed included toe-crushing of the north bottom 
(a)

Average drift [\%]

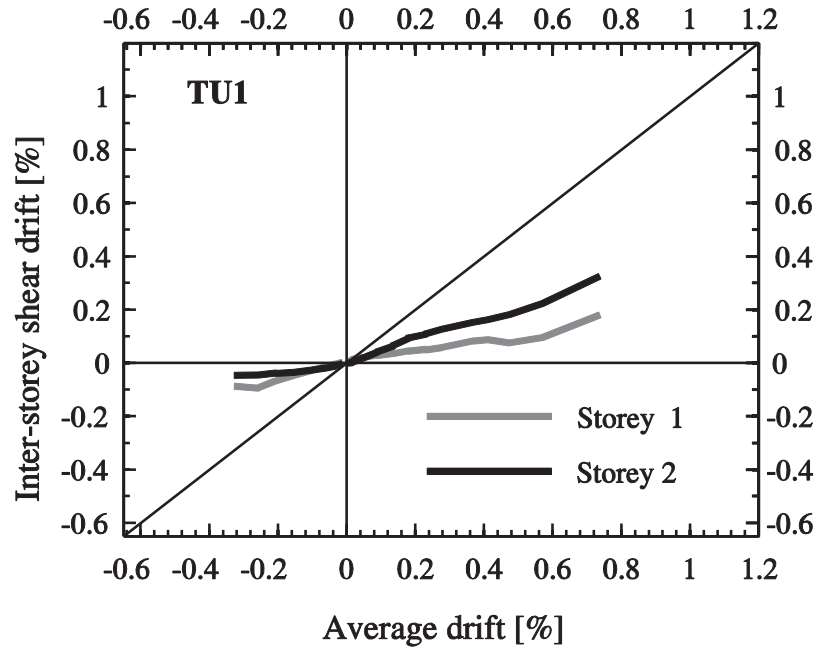

(b)

Average drift [\%]

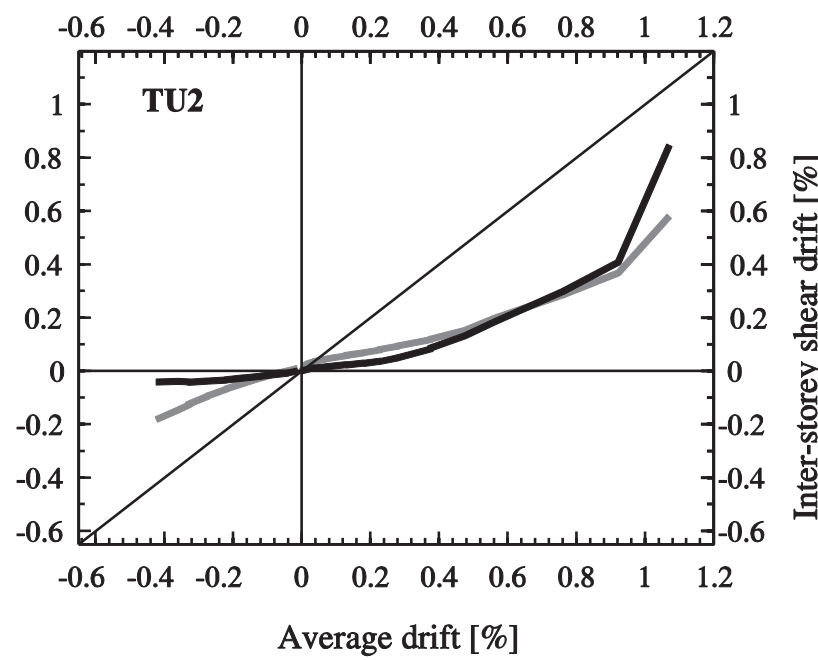

Fig. 8. URM inter-storey shear drift for TU1 (a) and TU2 (b).

corner of the first storey of the URM wall and steeply inclined shear cracks with maximum residual crack widths of $\sim 3 \mathrm{~mm}$ in the first storey whereas only thin inclined shear cracks appeared in the second storey. At the same drift demand for loading in the positive direction (LS26, $\delta=+0.3 \%$ ), the crack pattern of the URM wall comprised shear cracks distributed over the two storeys. Nevertheless, the cracks were larger in terms of number and width in the second storey since $\delta_{s}$ of the second storey was larger than that of the first storey (Fig. 8a).

Horizontal load failure initiated for loading in the negative rather than the positive direction as a consequence of the coupling by the two RC beams. For the negative loading direction the axial force in the URM wall increased and, as a result, the deformation capacity of the URM wall was reduced [26]. Petry and Beyer [26] showed that even if the failure mechanism remains the same, an increase in axial stress reduces the deformation capacity of URM walls. This was confirmed by the tests on the mixed structure, where for the negative loading direction, the URM toe crushing started at smaller displacement demands, leading to a smaller displacement capacity than for loading in the positive direction. Since the axial load and shear force were larger in the first than in the second storey of the URM wall, it was the first storey that failed. Hence the most critical loading direction was the negative one, i.e. when the axial force in the URM wall increased.

After LS27, the test was continued with half cycles in the positive loading direction only. Horizontal load failure of TU1 occurred during the half cycle with $\delta=+0.95 \%$ (LS33, Fig. 9c), i.e. at a drift demand around three times the drift capacity for loading in the negative direction. This underscores again the large influence of the axial load ratio on the deformation capacity of URM walls. Axial load failure of the first storey of the URM wall due to subsequent crushing of the compression struts of the fan pointing towards the compressed toe followed immediately afterwards and the second storey failed simultaneously along an inclined shear crack. Due to the larger base moment at the first storey, the length of the compressed toe of the URM wall was smaller at the first storey than at the second storey. As a consequence, the compressive strength of the masonry was reached first at the bottom storey, causing the axial load failure of the URM wall. In the previous cycle (LS32, $\delta=+0.8 \%$, Fig. 9b) the URM wall was already heavily damaged but still capable of bearing the gravity loads.

The cracks in the RC wall, which started developing from the very beginning of the test, were horizontal flexural cracks. At the end of the test, they extended over the entire first storey. The first inclined shear-flexure crack formed at $\delta=+0.8 \%$, indicating that the shear force carried by the RC wall had increased significantly since the stiffness of the RC wall was still increasing. At the end of the test (LS33, $\delta=+0.95 \%$ ), other two inclined shear-flexural cracks appeared and some of the longitudinal reinforcing bars at the north edge of the RC wall had yielded but the RC wall was far from failure.

The RC beams connecting the two walls deformed primarily in flexure and at a drift of $\pm 0.05 \%$ the first flexural cracks at the ends of the beams appeared. During the test, the length over which the beams were cracked increased and at the north end of the beam the cracked length of the beam penetrated more and more into the URM wall. At $\delta=+0.3 \%$, the cracked beam length penetrating the URM wall was $20 \mathrm{~cm}$ long and at $\delta=+0.8 \%$ it had increased up to $70 \mathrm{~cm}$. At the end of the test, the longitudinal top reinforcement bars at the north end of the beams had yielded.

\subsubsection{TU2}

The axial loads applied at the top of the RC and URM walls of TU2 were reduced when compared to TU1 (Section 2.1). As a consequence, the URM wall of TU2 exhibited, in particular for the positive direction of loading, a rocking behaviour, while the behaviour of the URM wall of TU1 was governed by shear deformations.

During the first cycles ( $\delta=0.025 \%$ ), horizontal cracks formed at the base of the RC and the URM wall of TU2. With increasing drift demand, the cracks became longer and additional horizontal cracks formed further up the wall. Both storeys of the URM wall displayed a clear rocking behaviour until at $\delta=0.15 \%$ inclined shear cracks formed in the first storey. The shear cracks followed initially the joints but from cycles with $\delta=0.2 \%$ onwards they passed also through the bricks. At this stage, inclined shear-flexure cracks developed in the first storey of the RC wall. In the second storey of the URM wall inclined shear cracks appeared at $\delta=0.25 \%$.

Until $\delta=0.25 \%$, the crack pattern developing for the positive and negative loading direction were rather similar. At larger cycles, for the negative direction of loading, the behaviour of the first storey of the URM wall changed from rocking to a prevalent shear mode, which was associated with the formation of large inclined shear cracks, mainly in the first storey, until $\delta=-0.4 \%$ (LS33 Fig. 9d). At this drift demand the horizontal resistance of the test unit dropped by $10 \%$. The horizontal force was immediately reduced to zero to avoid axial load failure of the URM wall. The 


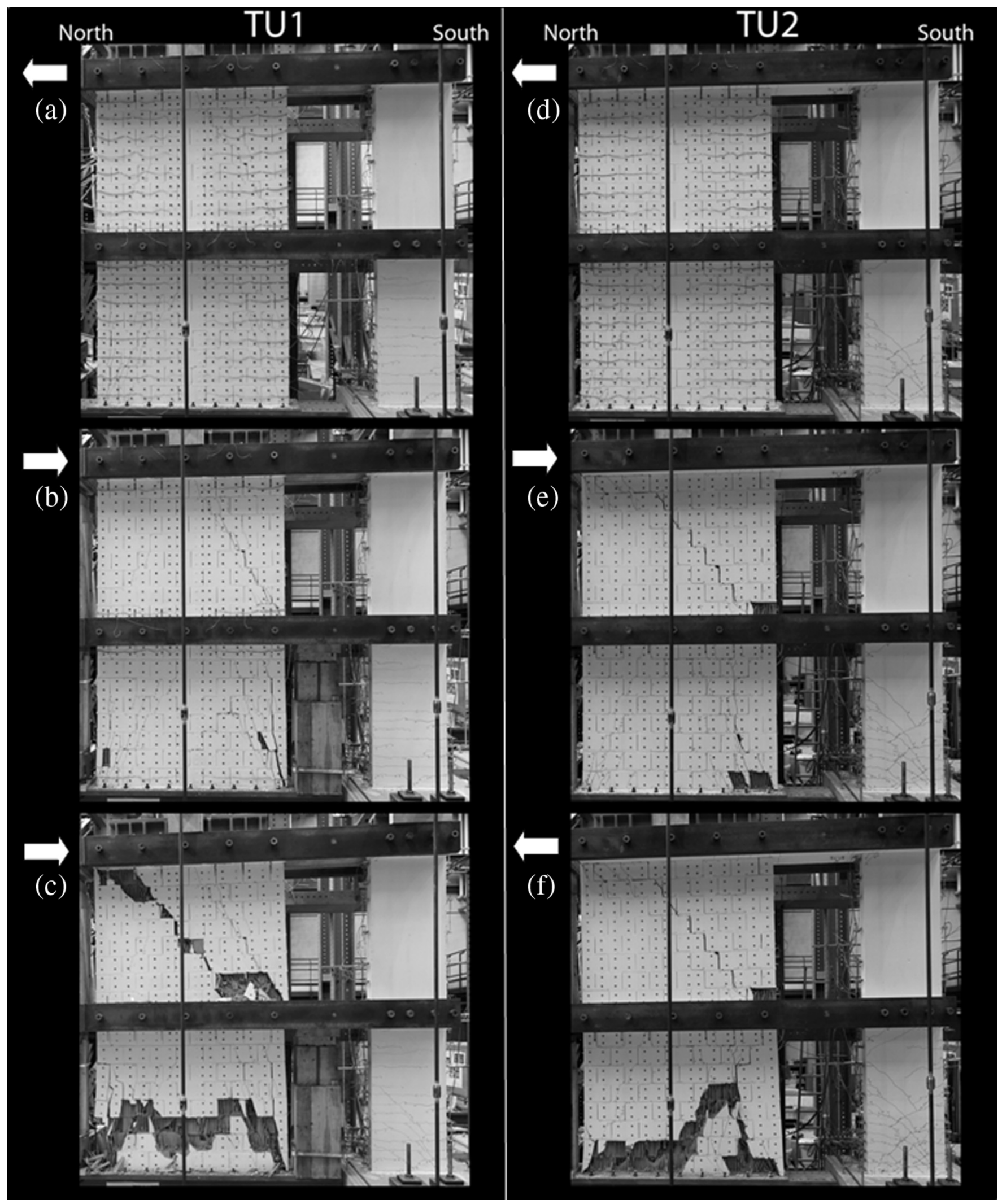

Fig. 9. LEFT: crack pattern of TU1 at $\delta=-0.3 \%$, LS27 (a), $\delta=+0.8 \%$, LS32 (b) and $\delta=+0.95 \%$, LS33 (c). RIGHT: crack pattern of TU2 at $\delta=-0.4 \%$, LS33 (d), $\delta=+1.12 \%$, LS38 (e) and $\delta=-0.6 \%$, LS39 (f).

crack pattern in the URM wall comprised in the first storey a fan pointing towards the compressed toe with residual crack widths up to $\sim 2 \mathrm{~mm}$. At the north bottom corner toe crushing was observed. The second storey was crossed by one thin shear crack.
The horizontal cracks at the base of the second storey of the URM still opened up significantly, indicating that at the second storey the prevalent mode was flexural. As for TU1, due to the coupling by the RC beams and the resulting axial force variation 
(a)

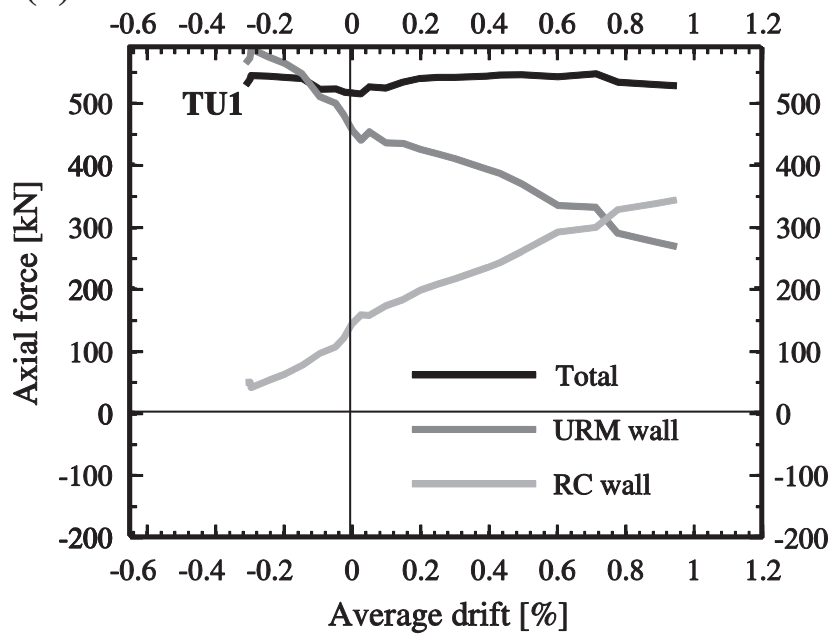

(b)

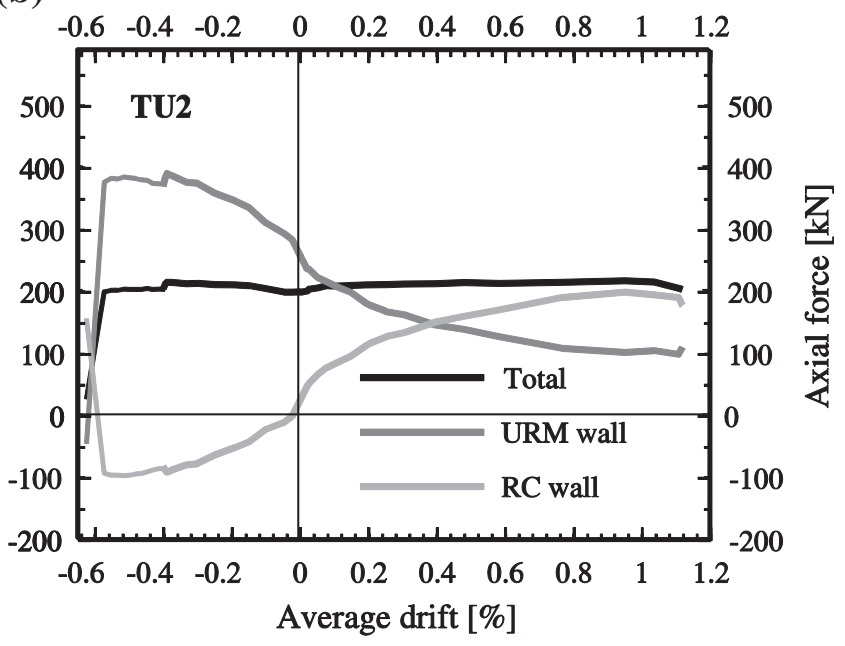

Fig. 10. Axial forces at the wall bases as a function of the imposed drift: (a) TU1, (b) TU2.

for the two directions of loading, the deformation capacity was smaller in the negative than in the positive loading direction.

After LS33, the test was continued with half cycles in the positive loading direction only. With each cycle, the inclined shear cracks in the two storeys of the URM wall and the vertical splitting cracks at the toe of the walls, which were caused by the rocking motion, increased in width and number. At LS38 $(\delta=+1.12 \%$, Fig. 9e), the residual width of the shear cracks in the first and second storey were $\sim 6 \mathrm{~mm}$ and $\sim 10 \mathrm{~mm}$, respectively. It was found in fact that, for this drift demand $(\delta=+1.12 \%)$, the inter-storey shear drift $\delta_{s}$ of the second storey was larger than that of the first storey (Fig. 8b). At this stage, the maximum residual crack width in the RC wall was around $1 \mathrm{~mm}$ and several longitudinal bars had yielded. However, the RC wall was still in an excellent state and far from failure. At LS38 the horizontal load dropped by around $20 \%$ and therefore the damage state is comparable to TU1 at the final load step (LS33, $\delta=+0.95 \%$ ). Due to the reduced axial force, the drift capacity of TU2 was therefore about $20 \%$ larger than that of TU1.

As for TU1, the RC beams deformed primarily in flexure. The first flexure cracks appeared at the edges of the beams at $\pm 0.05 \%$ and increased in number and width during the test. At the north end of the beams the cracked length penetrated deeper into the URM wall and, at the end of the test, the longitudinal top reinforcements at the north side of the beams had yielded. Since the negative loading direction is the more critical one, it was decided to finish the test by applying one last half cycle in this direction. At a drift of approximately $\delta=-0.6 \%$ (LS39, Fig. 9f) the horizontal load failure of the first storey of the URM wall was followed almost immediately by its axial load failure. The latter was triggered by the toe-crushing of the north bottom corner of the first storey of the URM wall and produced, from the north side towards the south side, the crushing of the bricks along the base of the URM wall.

\subsection{Hysteretic behaviour}

Fig. 10 shows the envelope of the axial forces and Fig. 11 the hysteresis of the base shears as a function of the drift of the test unit. Due to the coupling by the RC beams, the two units behaved differently when loaded in the positive and the negative direction (for the sign convention concerning the loading directions see Fig. 4a): in the positive one, the axial force in the URM wall decreased whereas in the negative direction the axial force in the URM wall increased (Fig. 10). Though the vertical forces applied to the walls differed between TU1 and TU2, the trends observed for the variation of axial and shear forces at the wall bases were rather similar. The following observations hold therefore for both specimens.

The vertical forces that were applied by means of jacks and bars at the top of the walls were controlled to remain approximately constant throughout the test. The total axial force at the test unit's base was therefore also constant. The variation in axial load at the base of the RC and the URM wall yields from the shear forces transmitted by the RC beams. For very small drifts $(\delta=0.025 \%)$ the beams were uncracked and the axial forces at the base of the walls varied strongly with $\delta$. For drifts larger than $\delta=0.025 \%$ flexural cracks formed at the beam ends and, as a consequence, the variation in axial force with $\delta$ decreased. A further decrease in slope was observed for drifts larger than $0.8 \%$ when the top longitudinal reinforcements of the first storey RC beam started to yield and the effective length of the beams increased due to uplift of the RC beam from the URM wall.

Due to the increase in axial force, the URM wall was stronger when the load was applied in the negative direction. However, an increase in axial force results also in a reduction of deformation capacity (see Section 3.1.2 and [26]). For this reason, in both test units, the URM walls lost their horizontal strength first in the negative loading direction leading to a drop in the test unit's lateral strength of $20 \%$ and $10 \%$ for TU1 and TU2, respectively (Fig. 11a and $b$ ).

For loading in the positive direction the axial force in the URM decreased with increasing drift demand. For drift demands larger than $+0.3 \%$ (TU1) and $+0.2 \%$ (TU2), the horizontal strength of the URM wall decreased. This strength deterioration was very pronounced for the URM wall of TU1, the bahaviour of which was dominated by shear failure with a rapid strength and stiffness degradation. On the other hand, TU2's URM wall displayed a rocking behaviour for loading in the positive direction, which was not accompanied by a fast strength degradation. The loss in strength of TU2's URM wall is therefore chiefly caused by the decrease in axial force in the URM wall. At the same time, due to the presence of the RC wall, the total base shear of both test units for loading in the positive and negative direction did not deteriorate until the end of the test because the relatively slender RC walls remained over a large range of drifts elastic. They could therefore somewhat compensate the gradual loss in strength due to the softening of the URM walls. The system's horizontal load failure was, for both test units, caused by the axial load failure of the URM wall. The RC walls underwent only relatively limited ductility demands and at the 
(a)

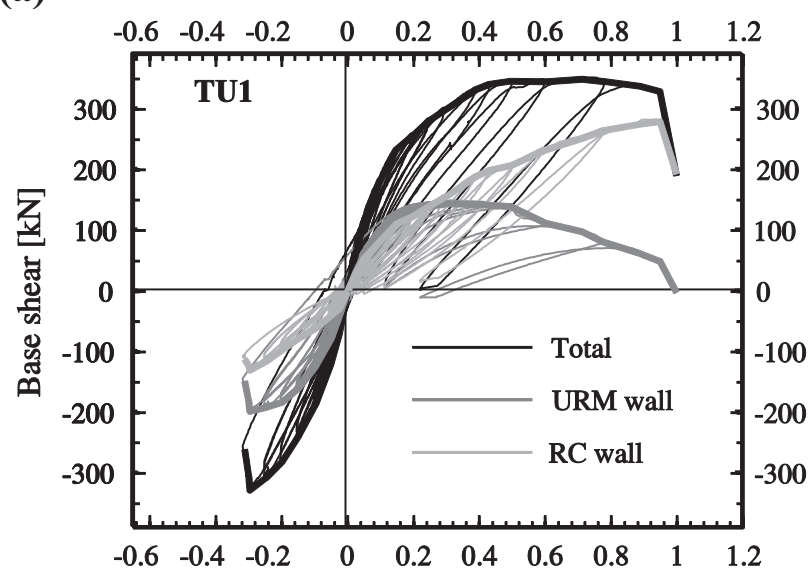

(c)

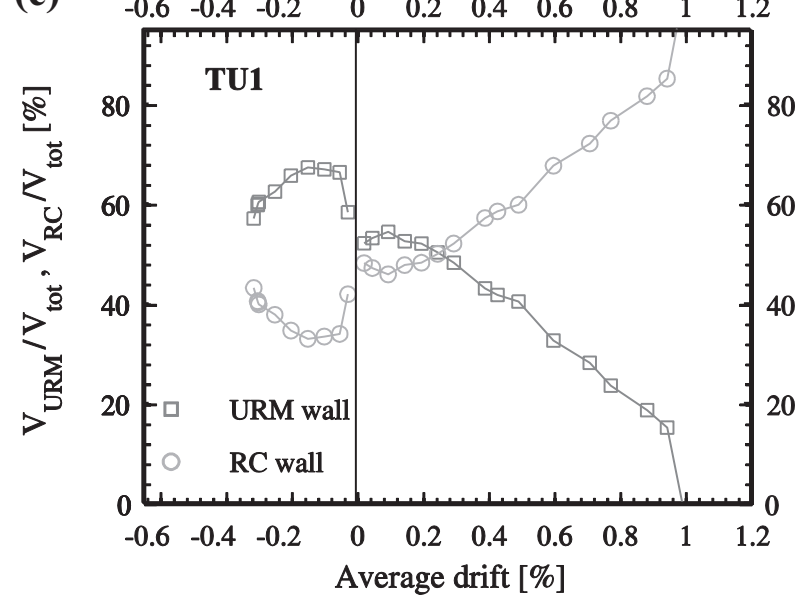

(b)

Average drift [\%]

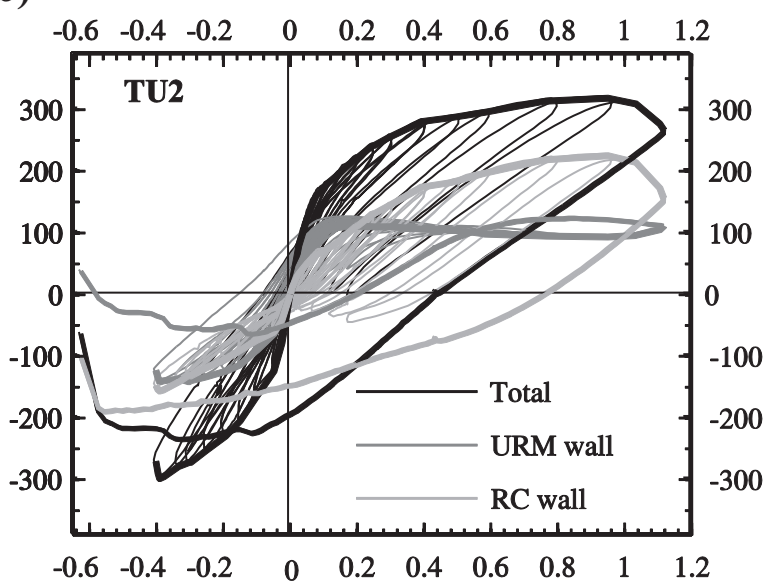

(d)

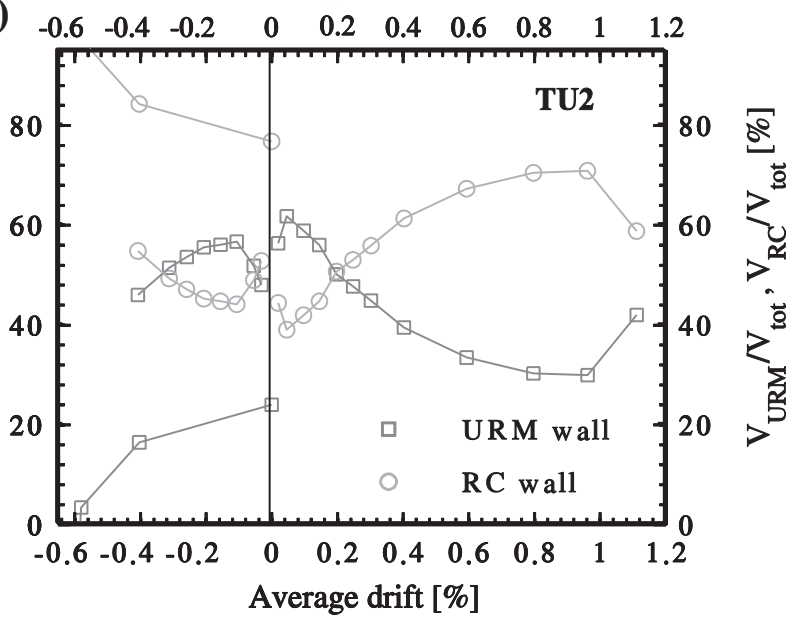

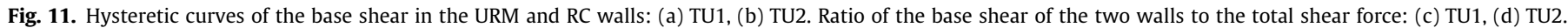

Table 6

Percentage of base shear taken by the URM wall in comparison to the total base shear for selected drift demands.

\begin{tabular}{|c|c|c|c|c|}
\hline \multirow[t]{2}{*}{ Nominal drift (\%) } & \multicolumn{2}{|l|}{ TU1 } & \multicolumn{2}{|l|}{ TU2 } \\
\hline & $V_{\text {URM }} / V_{\text {tot }}(\%)$ & Total $(\mathrm{kN})$ & $V_{\text {URM }} / V_{\text {tot }}(\%)$ & Total $(\mathrm{kN})$ \\
\hline+0.1 & $54 \%$ & 181 & 59 & 179 \\
\hline-0.1 & $67 \%$ & -186 & 55 & -165 \\
\hline+0.3 & $48 \%\left({ }^{*}\right)$ & 300 & $43\left(^{*}\right)$ & 257 \\
\hline-0.3 & $60 \%\left({ }^{*}\right)$ & -328 & 51 & -272 \\
\hline+0.4 & $43 \%$ & 333 & 38 & 280 \\
\hline-0.4 & - & - & $47(*)$ & -299 \\
\hline+0.6 & $32 \%$ & 345 & 33 & 295 \\
\hline+0.95 & $15 \%$ & 328 & 29 & 319 \\
\hline+1.12 & - & - & 41 & 226 \\
\hline
\end{tabular}

Values marked with an asterisk $\left({ }^{*}\right)$ indicate when the URM wall's strength was maximum.

end of the tests were still far from failure. As a consequence, they could have been designed, according to EN 1998-1 [27], for medium ductility ("DCM").

The URM walls of TU1 and TU2 carried approximately 50\% of the total base shear when responding elastically, that is for drifts lower than $0.025 \%$. With drifts between $0.025 \%$ and $0.1 \%$, the base shear absorbed by the URM wall increased; for larger drift demands, the URM wall carried a decreasing but still significant portion of the system's base shear regardless the direction of loading (Fig. 11c and d). Table 6 summarises the base shear distribution between the walls for the following limit states:

(i) $\delta= \pm 0.1 \%$ : no significant stiffness degradation of the URM wall;

(ii) $\delta= \pm 0.3 \%$ (TU1) and $\delta= \pm 0.4 \%$ (TU2): horizontal load failure of the test units for the negative loading direction;

(iii) $\delta=+0.6 \%$ : URM wall heavily damaged: strength of TU1's URM wall dropped by 20\%; crack pattern of TU2's URM wall mainly developed (both storeys displayed horizontal cracks due to the rocking behaviour and inclined cracks associated to the onset of the toe-crushing and the shear deformations);

(iv) $\delta=+0.95 \%$ and $\delta=+1.12 \%$ : onset of horizontal load failure of the test units for loading in the positive direction.

Table 6 shows that for both loading directions, until $\delta= \pm 0.3 \%$ the URM wall carried more than $40 \%$ of the total base shear. For larger drifts the URM wall's strength deteriorated and the portion of base shear carried by the URM wall decreased. For TU2, during the last cycle $(\delta=+1.12 \%)$ the base shear carried by the URM wall increased with respect to the previous load step because the second storey of the URM wall changed its primary deformation from flexural to shear. Since the RC beams continued enforcing the same horizontal displacement at the floor levels, additional axial forces developed in the beams which increased the shear 
force taken by the URM wall and, on the other hand, decreased the base shear of the RC wall.

\section{Conclusions and outlook}

This paper presents the results of two quasi-static cyclic tests on mixed RC-URM wall structures. Although many multi-storey residential buildings in Central Europe are constructed as mixed RC-URM wall buildings, experimental evidence on their seismic behaviour was missing. It is believed that this experimental campaign will contribute to the understanding of such mixed structures and will help to develop adequate seismic design guidelines, which allow for the interaction of the two different types of structural members and exploit the full deformation and force capacity of such mixed structures. This is necessary since in practice often oversimplified design assumptions are used, such as neglecting the lateral strength and stiffness of the masonry walls.

The tests have shown that, for mixed structures with slender RC walls, (i) the ultimate drift was always controlled by the URM walls which attained horizontal and axial load failure when the RC walls were far from failure. As a consequence, (ii) the RC walls can be generally designed, according to EN 1998-1 [27], for medium ductility ("DCM"). Since the deformation capacity of the URM wall decreases with increasing axial load ratio [26], (iii) the most critical loading direction in terms of ultimate drift of the test units was the direction for which the axial force in the URM wall increased. The variation in axial force results from the shear forces transferred by the RC beams which represented the effective width of RC slabs. In addition, (iv) it was found that the loss of strength due to the softening of the URM wall was somewhat compensated by the slender RC wall which remained over a large range of drifts elastic. Furthermore, unlike for buildings with URM walls only, (v) inelastic deformations in the URM walls tend to distribute over the height of the structure and do not concentrate in the first storey.

The tests provided high quality experimental data which will be used to validate numerical models of mixed RC-URM wall structures. This is necessary since important design quantities such as the distribution of the base shear between RC and URM walls proved strongly sensitiveness to the modelling assumptions $[2,3]$. Once such models have been validated, a large variety of mixed RC-URM wall systems will be studied. For example, (i) different wall length ratios of RC and URM walls or (ii) the effect of different masonry types can be evaluated. The results of such analyses will form the basis of force-based and displacement-based design guidelines for mixed RC-URM wall systems.

\section{Acknowledgments}

Professor D. Kuchma is gratefully acknowledged for his advice on the design of the test set-up. The authors would also like to thank the staff of the laboratory of the Institute of Civil Engineering (IIC) at the EPF Lausanne where the tests were performed, in particular S. Demierre, G. Guignet, and G. Rouge.

\section{References}

[1] Magenes G. Masonry building design in seismic areas: recent experiences and prospects from a European standpoint. Keynote address. In: Proceedings of "1st European conference on earthquake engineering and seismology". Geneva (Switzerland); 2006.

[2] Paparo A, Beyer K. Pushover analyses of mixed RC-URM wall structures. In: Proceedings of "15th world conference on earthquake engineering". Lisbon (Portugal); 2012.
[3] Casoli D. Assessment of existing mixed RC-masonry structures and strengthening by RC shear walls. A dissertation submitted in partial fulfilment of the requirements for the master degree in earthquake engineering. Pavia (Italy): IUSS Press; 2007.

[4] Cattari S, Lagomarsino S. Seismic assessment of mixed masonry-reinforced concrete buildings by non-linear static analyses. Earthquake Struct 2013; $4(3)$

[5] Cattari S. Modellazione a telaio equivalente di structure esistenti in muratura e miste muratura-c.a.: formulazione di modelli sintetici. PhD thesis, XIX Ciclo. Pavia (Italy); 2007.

[6] Liberatore L. Decanini LD, Benedetti S. Le strutture miste muratura-cemento armato: uno stato dell'arte. $12^{\circ}$ Convegno Nazionale L'ingegneria Sismica in Italia. Pisa (Italy); 2007.

[7] Tomazevic M, Modena C, Velechovsky T. Seismic behaviour of mixed structural systems with peripheral masonry walls and internal RC columns: an earthquake simulator study. In: Proceedings of "5th north American masonry conference”. Urbana Champaign (USA); 1990.

[8] Alessi A, Diotallevi PP, Jurukovski D, Petkovski M, Tashkov L, Zarri F. Shaking table test of reduced scale model of brick masonry building. In: Proceedings of "9th European conference on earthquake engineering". Moscow (Russia); 1990.

[9] Alessi A, Diotallevi PP, Merli M, Zarri F, Jurukovski D, Tashkov L, et al. Comparison of dynamic properties of a mixed reinforced concrete masonry building before and after strengthening. In: Proceedings of "10th European conference on earthquake engineering”. Vienna (Austria); 1994.

[10] Jurukovski D, Taskov L, Petkovski M, Krestevska L. Basic and applied research study for seismic modelling of mixed reinforced concrete - masonry buildings. Shaking table test of reduced scale model. IZIIS test report no 89/66. Skopje (Macedonia); 1989.

[11] Jurukovski D, Taskov L, Petkovski M, Krestevska L. Basic and applied research study for seismic modelling of mixed reinforced concrete - masonry buildings. Shaking table test of reduced scale repaired model. IZIIS test report no 89/75. Skopje (Macedonia); 1989.

[12] Jurukovski D, Taskov L, Petkovski M, Krestevska L. Basic and applied research study for seismic modelling of mixed reinforced concrete-masonry buildings. Shaking table test of reduced scale model strengthened by external reinforced concrete walls. IZIIS test report no 91/01. Skopje (Macedonia); 1991.

[13] Jurukovski D, Taskov L, Petkovski M, Krestevska L. Basic and applied research study for seismic modelling of mixed reinforced concrete - masonry buildings. Shaking table test of reduced scale model strengthened by concrete central core. IZIIS test report no 91/92; Skopje (Macedonia); 1991.

[14] Jurukovski D, Krstevska L, Alessi R, Diotallevi PP, Merli M, Zarri F. Shaking table tests of three four-storey brick masonry models: original and strengthened by RC core and by RC jackets. In: Proceedings of "10th world conference on earthquake engineering”. Madrid (Spain); 1992.

[15] Priestley JMN, Calvi GM, Kowalsky MJ. Displacement-based seismic design of structures. Pavia (Italy): IUSS Press; 2007.

[16] CEN. Eurocode 6: design of masonry structures, Part 1: general rules for reinforced and unreinforced masonry structures. EN 1996-1-1:2005. Brussels (Belgium): European Committee for Standardisation; 2005.

[17] CEN. Eurocode 6: methods of test for masonry units, Part 1: determination of compressive strength. EN 772-1:2000. Brussels (Belgium): European Committee for Standardisation; 2000.

[18] CEN. Eurocode 6: methods of test for masonry, Part 1: determination of compressive strength. EN 1052-1:1998-12. Brussels (Belgium): European Committee for Standardisation; 1998.

[19] CEN. Eurocode 6: Methods of test for masonry, Part 3: determination of the initial shear strength. EN 1052-3:2002. Brussels (Belgium): European Committee for Standardisation; 2002.

[20] Beyer K, Abo-El-Ezz A, Dazio A. Quasi-static cyclic tests on different types of masonry spandrels. IBK report no. 327. Zurich (Switzerland); 2010.

[21] SIA. SIA262/1: Concrete structures - supplementary specifications. Building code, Swiss Society of Engineers and Architects (SIA). Zurich (Switzerland); 2003.

[22] Chen W. Double punch test for tensile strength of concrete. ACI J 1970;67: 993-5.

[23] Calvi GM, Kinglsley GR. Problems and certainties in the experimental simulation of the seismic behaviour of the seismic response of MDOF structures. Eng Struct 1996;18(3):213-26.

[24] Lequesne RC, Parra-Montesinos GJ, Wight JK. Test of a coupled wall with high performance fiber-reinforced concrete coupling beams. ACI Struct J 2009;265: $1-18$.

[25] NDI. Optotrak Certus HD, Northern Digital Inc., Waterloo, Ontario (Canada); 2009. <http://www.ndigital.com/industrial/certushd.php>.

[26] Petry S, Beyer K. Influence of boundary conditions and size effect on the drift capacity of URM walls. Eng Struct. 2014;65:76-88.

[27] CEN. Eurocode 8: design of structures for earthquake resistance, Part 1: general rules, seismic actions and rules for buildings. EN 1998-1:2004. Brussels (Belgium): European Committee for Standardisation; 2004. 